\title{
ARTICLE
}

\section{Measurement of environmental gamma-ray dose rate around the Nuclear Fuel Cycle Engineering Laboratories, JAEA}

\author{
Tomoko MIZUTANI ${ }^{1}$, Toshimitsu ONUMA ${ }^{1}$, Masamitsu SUGAI ${ }^{2}$, Hajime WATANABE ${ }^{2}$, \\ Masato MORISAWA ${ }^{1}$, Masanori TAKEYASU ${ }^{1}$, Shuichi SUMIYA ${ }^{1}$ \\ ${ }^{1}$ Japan Atomic Energy Agency, Tokai-mura, Ibaraki, Japan \\ ${ }^{2}$ Joyo Industry Co. Ltd, Tokai-mura, Ibaraki, Japan
}

\begin{abstract}
The Nuclear Fuel Cycle Engineering Laboratories (NCL), JAEA operates the Tokai Reprocessing Plant (TRP), plutonium fuel fabrication facilities and the supplemental facilities. In the terrestrial environment, environmental gamma-ray dose rate was measured continuously using an energy-thermo-compensation-type $\mathrm{NaI}(\mathrm{Tl})$ scintillation detector. The data of environmental dose rate measured in 5 monitoring stations and 8 monitoring posts were collected and analyzed to monitor on real-time. This paper summarizes the monitoring data of environmental dose rate around the NCL during the past 10 year (fiscal 1998-2007). The averages of the environmental dose rate for all monitoring stations and posts were in the range of 32-45 $\mathrm{nGy} \mathrm{h}^{-1}$. The long-term variation in the environmental dose rate was not found. The cases of the short-term increases occurred by the operations of the facilities in the NCL were concluded to the discharges of ${ }^{85} \mathrm{Kr}$ from the TRP, transportation of MOX fuels or radioactive solid wastes, X-ray generator to calibrate the radiation monitoring instruments. The other cases to affect the change of the environmental dose rate were the scavenging of the airborne natural radionuclides, a patient cured by the radiation therapy and the shield effect by cars.
\end{abstract}

KEYWORDS: Tokai Reprocessing Plant (TRP), environmental gamma-ray dose rate, long-term variation, short-term variation, krypton-85 $\left({ }^{85} \mathrm{Kr}\right)$, external effective dose, cloud gamma, energy index

\section{Introduction}

The nuclear fuel cycle is a promoted technology to supply the stable energy for the future world. The Nuclear Fuel Cycle Engineering Laboratories (NCL), JAEA has the Tokai Reprocessing Plant (TRP), plutonium fuel fabrication facilities, radioactive waste treatment facilities and radio isotope treatment laboratories. The TRP has reprocessed the total amount of 1,100 tons of spent fuels used at PWRs, BWRs and an advanced thermal reactor (ATR, called FUGEN) since the start of its operation in 1977. The TRP has completed the contract-based reprocessing with electric companies on March 2007 and finished its operation on May 2007 to the intentional maintenance. The plutonium fuel fabrication facilities have investigated to fabricate mixed oxide (MOX) fuels loaded to the fast breeder reactor (FBR, called JOYO and MONJYU) and the ATR since 1967.

Environmental radiation monitoring around the NCL has been conducted for estimating the public dose and the long-term accumulation of radionuclides in the environment. The objects of the monitoring are the measurements of the environmental doses (gamma-ray dose rate and the cumulative dose) and the concentrations of radionuclides in environmental samples. Among them, the short-term change of the radiation level is observed on the purpose to collect the supplemental data for the estimation of the external effective dose resulted from ${ }^{85} \mathrm{Kr}$ discharged from the TRP and the surveillance for the accidental releases of the

*Corresponding Author, E-mail:mizutani.tomoko@jaea.go.jp

(C) Atomic Energy Society of Japan radionuclides from nuclear facilities.

This paper summarizes the monitoring data of the environmental gamma-ray dose rate (environmental dose rate) around the NCL during the past 10 year (fiscal 1998-2007) in both point of the long-term variation and the short-term variations.

\section{Monitoring method}

In the environmental monitoring, environmental dose rate from $50 \mathrm{keV}$ to $3 \mathrm{MeV}$ of its gamma-ray energy range was measured continuously using a $2^{\prime} \phi \times 2$ ' energy-thermo -compensation-type $\mathrm{NaI}(\mathrm{Tl})$ scintillation detector. The energy compensation system was adopted by means of DBM (discrimination bias modulation). ${ }^{1)}$ Five monitoring stations (ST) and eight monitoring posts (P) were installed inside and outside the NCL. The location of the monitoring stations and posts is shown in Fig. 1.

The data of the environmental dose rate has been collected at one-minute intervals (1-minute value) by a telemeter system in the environmental data processing room. 10-minute value and 1-hour value were calculated on the assumption of the average value of 10 or 60 continuously pieces of 1-minute value, respectively. The latest information of the 10-minute value and 1-hour value were open to the public to web. To add them, the trend graph of the 1-minute value was displayed in Intranet. The exhaust gaseous monitoring data in the main stack of the TRP and the meteorological data (e. g., rain, wind direction and velocity) observed in the NCL were also collected and become supplementary information to analyze a cause of the variations of the environmental dose rate. These systems 


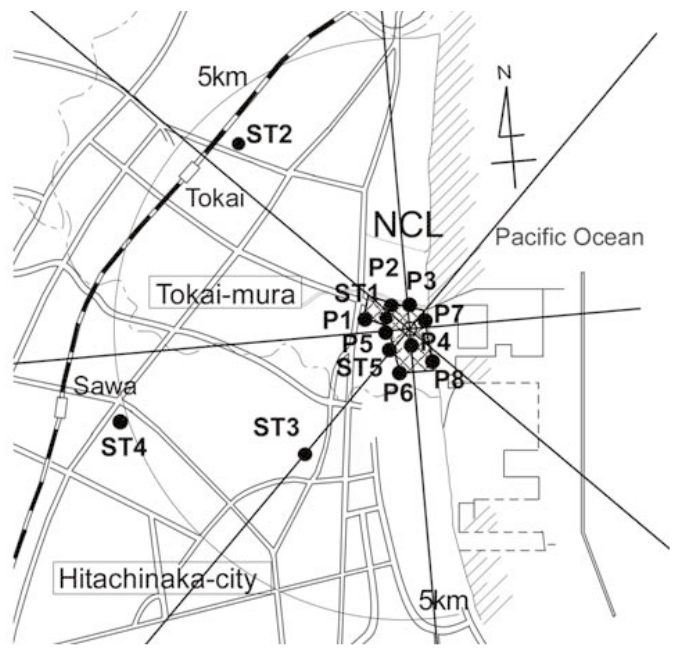

Fig. 1 Location of Nuclear Fuel Cycle Engineering Laboratories, monitoring stations (ST) and monitoring posts (P)

were replaced from a mainframe to a workstation in 1997. Then the differential values of dose rate could easily monitor and analyze real-time by using the personal computer. The index of the incidence energy (energy index; a ratio of gamma-ray counts these passed the energy -compensation-circuit later and former) was used for the analysis. In some locations, the monitoring installations had renewed to the devises with a multi channel analyzer, but the method of the analysis was uniformly using the energy index for all monitoring locations.

\section{Results and discussions}

\section{Long-term variation}

The environmental dose rate during the past 10 year was shown in Table 1, except the value influenced by the criticality accident at the JCO in $1999^{2}$. The averages of the environmental dose rate for all locations were in the range of 32-45 $\mathrm{nGy} \mathrm{h}^{-1}$. The maximum 1-hour values were accompanied by the rainfall or the snowfall event. The level of these monitoring data was similar to the terrestrial gamma radiation level in Japan reported by Furukawa. ${ }^{3}$ The differences of the annual average of the environmental dose rate compared with the previous year were $\pm 3 \%$ for each location regardless of the operation of the TRP, except for the cases of the renewed of the instrument.

\section{Short-term variations}

The short-term increases of the environmental dose rate were observed mainly due to the scavenging of the airborne natural radionuclides. The cases of the short-term increases occurred by the operations of the facilities in the NCL were according to the discharges of ${ }^{85} \mathrm{Kr}$ from the TRP, transportation of MOX fuels or radioactive solid wastes, $\mathrm{X}$-ray generator to calibrate the radiation monitoring instruments. The other cases to affect the change of the environmental dose rate were assumed to a patient cured by the radiation therapy and the shield effect by cars.

(1) Scavenging the airborne natural radionuclides

As shown in Table 1, the maximum 1-hour values were observed on December 26-27, 2003 or December 30, 2007
Table 1 Environmental dose rate (1-hour value) around the NCL at the fiscal period from 1998 to 2007

\begin{tabular}{|c|c|c|c|c|c|}
\hline \multirow{2}{*}{$\frac{\text { Location }}{\text { ST1 }}$} & \multicolumn{3}{|c|}{ Average $\pm 3 \sigma$} & \multicolumn{2}{|c|}{ Maximum (Date) } \\
\hline & 32 & \pm & 1.8 & 66 & (Dec. 27, 2003) \\
\hline ST2 & 35 & \pm & 2.4 & 68 & (Dec. 27, 2003) \\
\hline ST3 & 34 & \pm & 2.2 & 77 & (Dec. 26, 2003) \\
\hline ST4 & 32 & \pm & 1.7 & 75 & (Dec. 27, 2003) \\
\hline ST5 & 45 & \pm & 3.3 & 95 & (Dec. 27, 2003) \\
\hline $\mathrm{P} 1$ & 43 & \pm & 3.1 & 91 & (Dec. 27, 2003) \\
\hline $\mathrm{P} 2$ & 43 & \pm & 4.0 & 79 & (Dec. 27, 2003) \\
\hline P3 & 45 & \pm & 2.6 & 85 & (Dec. 26, 2003) \\
\hline P4 & 44 & \pm & 2.6 & 86 & (Dec. 30, 2007) \\
\hline P5 & 41 & \pm & 2.4 & 91 & (Dec. 27, 2003) \\
\hline P6 & 42 & \pm & 3.0 & 93 & (Dec. 26, 2003) \\
\hline P7 & 34 & \pm & 3.6 & 81 & (Dec. 30, 2007) \\
\hline P8 & 44 & \pm & 2.5 & 91 & (Dec. 26, 2003) \\
\hline
\end{tabular}

during the snowfall or the rainfall event. These values were about 1.8-2.4 times higher than average values. Takeyasu et al. reported that the increases of the environmental dose rate by the scavenging the short-lived Radon-progenies during the rainfall event were observed when the air mass came from the Eurasia. ${ }^{4}$ The trajectory analysis of the air mass using the METEX $^{5)}$ resulted that the air mass caused the snowfall or the rainfall event in both days were pass through the Eurasia.

(2) ${ }^{85} \mathrm{Kr}$ discharged from the TRP

The TRP has released the radionuclides into the atmosphere via three 90-m-high stacks by its operation of the fuel reprocessing. Almost all the noble-gases were discharged in the nuclear fuel shearing and dissolution processes. Figure $\mathbf{2}$ shows the variations of the environmental dose rate (10-minute value) observed on October 20-23, 2003. The sharp peaks of the environmental dose rate were observed at the ST or P located in the direction of leeward, when the large amount of ${ }^{85} \mathrm{Kr}$ exceeded $10 \mathrm{TBq} \mathrm{h}^{-1}$ was discharged in the shearing process and the forepart of the dissolution process. The TRP

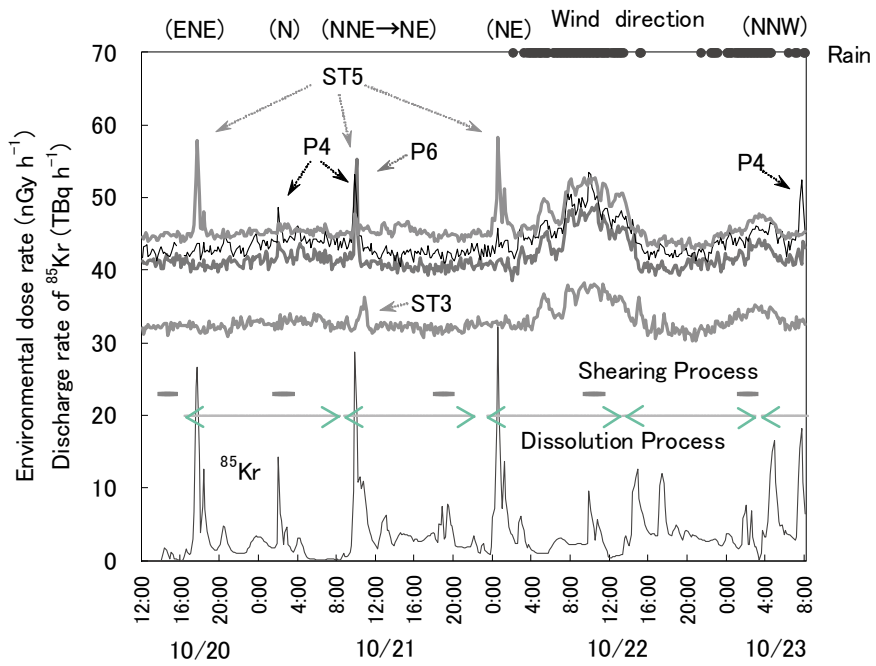

Fig. 2 Variations of the environmental dose rate during the nuclear fuel shearing and dissolution processes of the TRP 


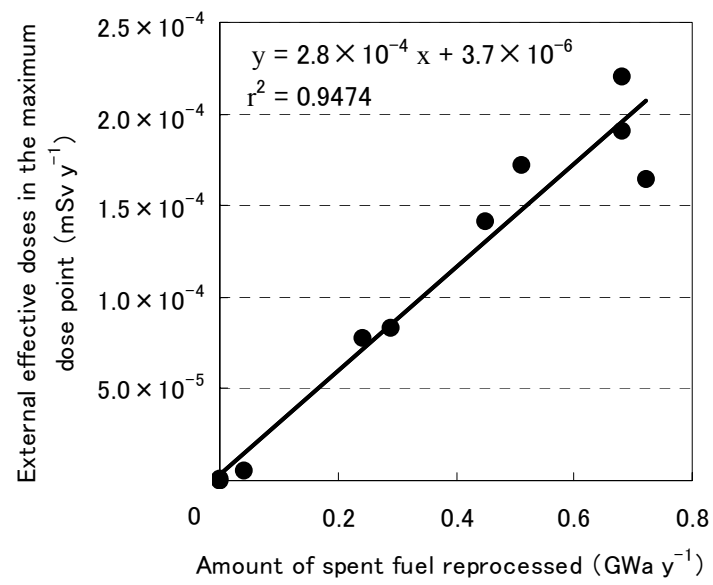

Fig. 3 Correlation with the external effective doses calculated for the cloud gamma by the mathematical model and the amount of spent fuel reprocessed in the TRP

conducted that the nuclear fuel shearing and dissolution processes in batch mode, the pattern of such a temporary increase of the environmental dose rate along the discharge amount of ${ }^{85} \mathrm{Kr}$ was due to the operating mode of the TRP.

By the way, because the level of the additional dose rate caused by ${ }^{85} \mathrm{Kr}$ discharged from the TRP was very low, it was difficult to estimate the public doses from the environmental monitoring data. The annual public doses for a hypothetical person have been calculated using the discharge data and mathematical models. ${ }^{6}$ ) The maximum dose point outside the periphery monitoring area of the NCL was evaluated in the vicinity of the site boundary of $500 \mathrm{~m}$ in the southwest direction except for fiscal 1999. Because of the maintenance of the exhaust equipment of the TRP in 1999, the change of the flow rate of the exhaust gases resulted the difference of the maximum dose point, $700 \mathrm{~m}$ in the southwest direction. The external effective dose calculated for the cloud gamma (cloud gamma dose) in the maximum dose point was on the order of $10^{-4} \mathrm{mSv} \mathrm{y}^{-1}$ in case of the TRP reprocessed the nuclear fuels and the order of $10^{-7} \mathrm{mSv} \mathrm{y}^{-1}$ when the TRP stopped its operation. Though the discharge amount of ${ }^{85} \mathrm{Kr}$ was somewhat different depending on the cooling time of the reprocessed fuels and the type of reactor burned the nuclear fuels, it was relatively proportional to the amount of fuel reprocessed. The cloud gamma dose evaluated by the calculation has related to the reprocessed amount of the spent fuels (see Fig.3). The cloud gamma dose from the ${ }^{85} \mathrm{Kr}$ discharged from the TRP was estimated to be $2.8 \times 10^{-4} \mathrm{mSv} \mathrm{GWa}^{-1}$.

(3) Transportation of nuclear materials

P4 was located in front of the gate of the plutonium fuel fabrication facilities. The temporal increases of the environmental dose rate, added 5-20 $\mathrm{nGy} \mathrm{h}^{-1}$ in 1-minute value continued a few minutes, were observed when a transportation truck that loaded MOX fuels or radioactive solid wastes generated by the MOX fuel fabrication processes passed the gate. The energy index declined when the wastes transported. On the other hand, the energy index had no change in case of MOX fuels (see Fig. 4(a)). At the point of the radiation control, the gamma-ray emitted from (a)
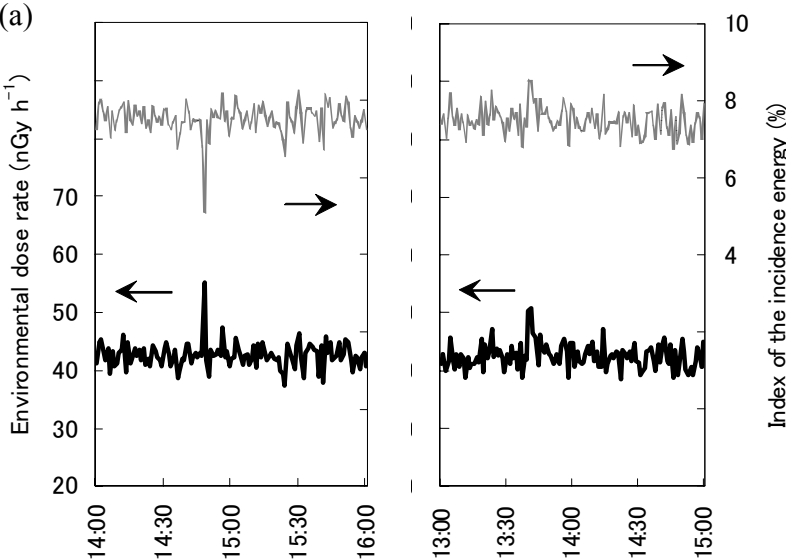

(b)

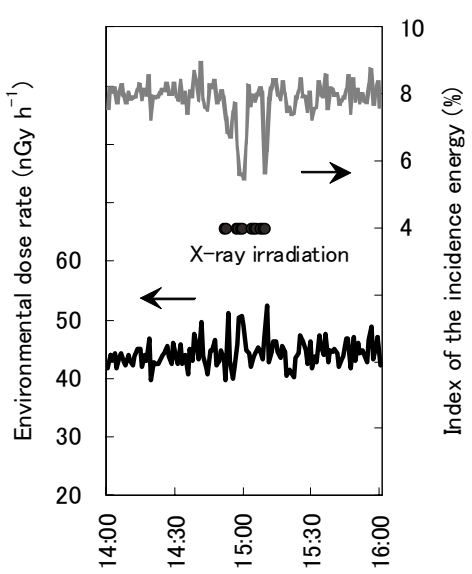

(c)

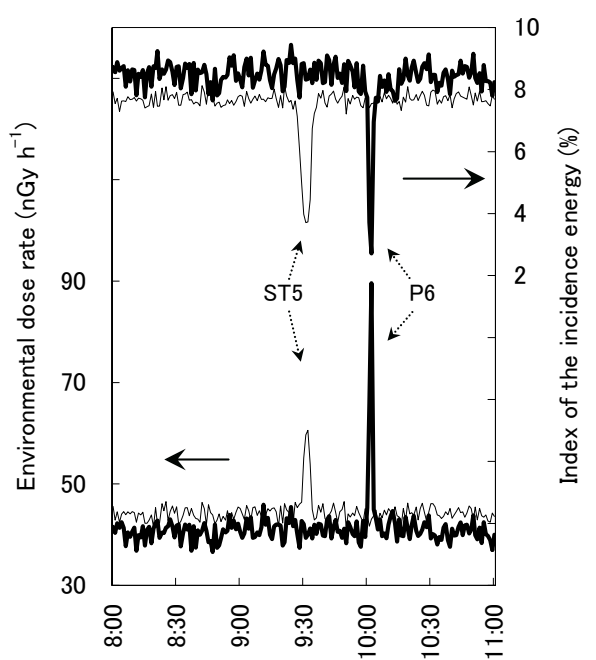

Fig. 4 Variations of the environmental dose rate and the index of the incidence energy; (a) transportation of the radioactive solid wastes on June 21, 2006 (left) and the MOX fuels on June 5, 2007 (right); (b) X-ray irradiation on August 23, 2007; (c) a patient cured by the radiation therapy on May 11, 2005

the fuel materials, uranium and plutonium, are disregarded except the gamma-ray energy of $208 \mathrm{keV}$ from ${ }^{237} \mathrm{U}$. However, MOX fuels contain ${ }^{241} \mathrm{Am}$ emitting the mean gamma-ray energy of $57.9 \mathrm{keV}$ as the impurities disintegrated from ${ }^{241} \mathrm{Pu}$ in its half-life of fourteen years. The difference of the trend of the energy index considered the difference of the content of ${ }^{241} \mathrm{Am}$ due to the elapsed time after plutonium had refined and the capability of the 
container for shield the gamma-ray.

(4) X-ray generator

The NCL installed in X-ray generator to calibrate the radiation monitoring instruments. $\mathrm{P} 8$ was in a place left by about $200 \mathrm{~m}$ away from the calibration facility. The increase of the environmental dose rate was observed in P8 while generating $X$ rays (see Fig. $\mathbf{4 ( b )}$ ). The additional dose rate was about 5-10 nGy $\mathrm{h}^{-1}$ and the continuance time was accorded with the time of irradiation. The energy index had decreased from $8 \%$ to $5-7 \%$. The gamma-ray energy that contributed to the increase of the environmental dose rate corresponded to $120-150 \mathrm{keV}$ and agreed well with the mean energy of $122 \mathrm{keV}$ evaluated by the gain of the X-ray generator.

(5) Patient cured by the radiation therapy

In ST5 and P6, the 1-minute values of the environmental dose rate were increased in 61 and $90 \mathrm{nGy} \mathrm{h}^{-1}$ by turns (see Fig. 4(c)). Both ST5 and P6 were away at about $1 \mathrm{~km}$ and their locations were adjacently the material place of the private company in ST5 and the general road in P6. The energy index had decreased from $8 \%$ to $3.7 \%$ in ST5 and from $9 \%$ to $2.7 \%$ in $\mathrm{P} 6$. The gamma-ray energy that contributed to the increase of the environmental dose rate corresponded to $100-120 \mathrm{keV}$. The result of the spectrum analysis with the multi channel analyzer installed in ST5 found the peak of the energy range from 50 to $150 \mathrm{keV}$ apparently, and supported the result of the energy index analysis. Recently, the radioactive medicine such as ${ }^{99 \mathrm{~m}} \mathrm{Tc}$ and ${ }^{67} \mathrm{Ga}$ emitting the mean gamma-ray energy of $141 \mathrm{keV}$ and $160 \mathrm{keV}$, respectively, are generally used. Therefore, it was assumed that the traffic of the patient cured by the radiation therapy became the cause of the increases of the environmental dose rate.

(6) Shield effect by cars

The decline of the environmental dose rate was observed in P2 faced to the parking area of the employee in the NCL. As shown in Fig. 5, the levels of the environmental dose rate in the daytime of work day clearly declined about $4 \mathrm{nGy} \mathrm{h}^{-1}$ in P2. This amount of the decline of the environmental dose rate was larger than the range of the day cycle due to the diffusion of the Radon-progenies. The variation of the environmental dose rate at night and holiday was comparable as P3 where no traffic and parking of cars. Sakaue et al. reported that the environmental dose rate measured by the $\mathrm{NaI}(\mathrm{Tl})$ scintillation detector fixed on the roof of a car declined $20 \%$ by the shield effect of the car compared with the case where there was no car. ${ }^{7)}$ Thus, it was concluded that the decline of the environmental dose rate was caused by the shield effect by cars in the location of adjoining the parking area.

\section{Conclusions}

The environmental dose rate has been continuously measured around the NCL. At the fiscal period from 1998 to 2007 , the long-term variation caused by the operation of the

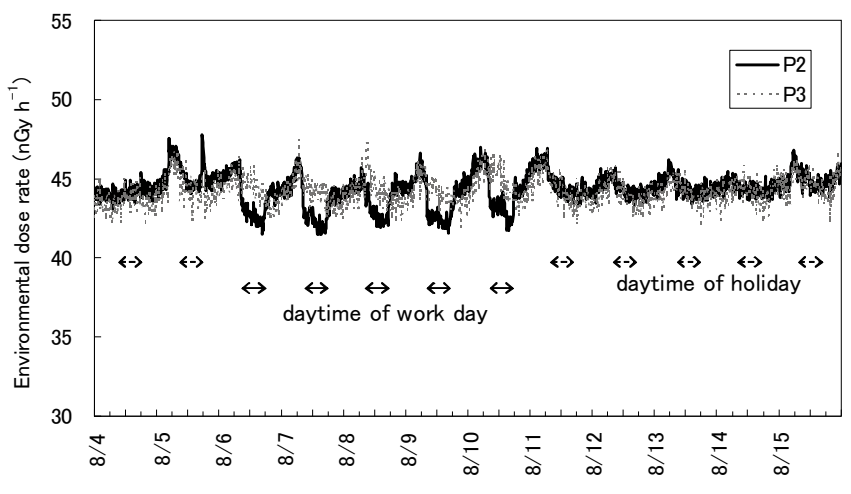

Fig. 5 Variations of the environmental dose rate in case of the shield effect by cars during August 4-15, 2007

TRP was not found. The external effective doses calculated for the cloud gamma by using the discharged data and the mathematical model were on the order of $10^{-4} \mathrm{mSv} \mathrm{y}^{-1}$ in case of the TRP reprocessed the nuclear fuels. The cloud gamma dose from the TRP estimated to be $2.8 \times 10^{-4} \mathrm{mSv}$ $\mathrm{GWa}^{-1}$. The short-term variations of the environmental dose rate caused by the ${ }^{85} \mathrm{Kr}$ discharged from the TRP, the transportation of nuclear materials, X-ray irradiation, a patient cured by the radiation therapy could presume the causes by using the data of the energy index and meteorological observation data.

\section{Acknowledgment}

The authors would like to thank K. Shiba, T. Yoshida and Y. Ito of Japan Atomic Energy Agency.

\section{References}

1) S. Moriuchi, A Dosimetric Instrument Based on the Spectrum Weighting Function Method for Environmental Radiation Measurements, JAERI-M 7066, Japan Atomic Energy Research Institute, (1977), [in Japanese].

2) K. Shinohara, et al., The Results of the Environmental Monitoring Related to the Criticality Accident in JCO, JNC-TN8440 2001-004, Japan Nuclear Cycle Development Institute, (2001), [in Japanese].

3) M. Furukawa, "Data synthesis for terrestrial gamma radiation level measured on the Japanese Islands and their adjacent ocean floor", Proc. Int. Conf. on Isotopes in Environmental Studies Aquatic Forum 2004, Monaco, Oct. 25-29, 2004, p.248 (2004).

4) M. Takeyasu, T. Iida, M. Takeishi, "Analysis of Rn-222 Concentration in the upper Atmosphere during Rainfall Using the Wet Scavenging Model for its Decay Products", Proceedings of AOCRP-2, Beijing, China, Oct. 9-13, 2006, p.752 (2006).

5) Y. Fujimura, Data Analysis and Graphic Display System for Atmospheric Research Using PC, CGER-M-14-2003, National Institute for Environmental Studies, Japan (2003).

6) K. Shinohara, T. Asano, "Environmental dose assessment for low-level radioactive effluents discharged from Tokai reprocessing plant", Health Physics, 62 [1], 58 (1992).

7) H. Sakaue, H. Fujimaki, K. Kato, H. Nakayama, "Outline of a New Carborne Radiation Monitoring System", Annual Report of the Niigata Prefectural Radiation Monitoring Center [5], p.45, Niigata Prefectural Radiation Monitoring Center, (2007), [in Japanese]. 